\title{
A comprehensive review of the SLMTA literature part 2: Measuring success
}

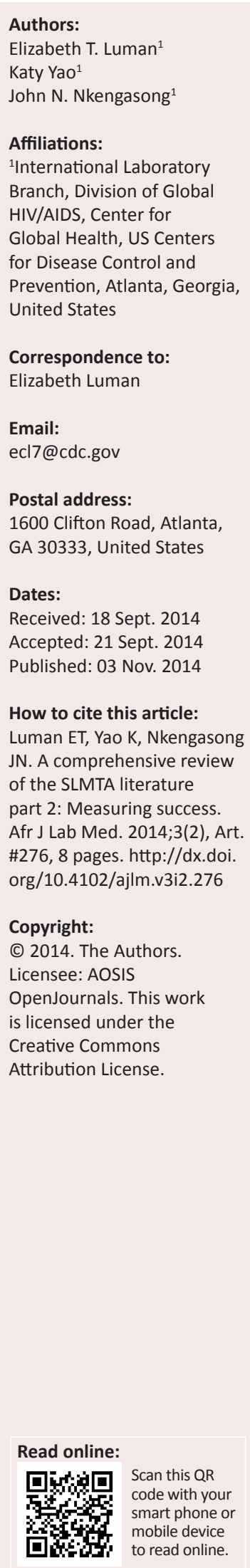

Background: Since its introduction in 2009, the Strengthening Laboratory Management Toward Accreditation (SLMTA) programme has been implemented in 617 laboratories in 47 countries.

Objective: We completed a systematic review of the published literature on SLMTA. The review consists of two companion papers; this article examines quantitative evidence presented in the publications along with a meta-analysis of selected results.

Methods: We identified 28 published articles with data from SLMTA implementation. The SLMTA programme was evaluated through audits based on a standard checklist, which is divided into 12 sections corresponding to the 12 Quality System Essentials (QSEs). Several basic service delivery indicators reported by programmes were also examined. Results for various components of the programme were reviewed and summarised; a meta-analysis of QSE results grouped by the three stages of the quality cycle was conducted for 126 laboratories in 12 countries.

Results: Global programme data show improved quality in SLMTA laboratories in every country, with average improvements on audit scores of 25 percentage points. Meta-analysis identified Improvement Management as the weakest stage, with internal audit $(8 \%)$ and occurrence management (16\%) showing the lowest scores. Studies documented 19\% - 95\% reductions in turn-around times, $69 \%-93 \%$ reductions in specimen rejection rates, $76 \%-81 \%$ increases in clinician satisfaction rates, $67 \%-85 \%$ improvements in external quality assessment results, $50 \%-66 \%$ decreases in nonconformities and $67 \%$ increases in staff punctuality.

Conclusions: The wide array of results reported provides a comprehensive picture of the SLMTA programme overall, suggesting a substantive impact on provision of quality laboratory services and patient care. These comprehensive results establish a solid datadriven foundation for program improvement and further expansion.

\section{Introduction}

Quality laboratory services are critical for ensuring optimal patient care and comprehensive public health response; however, laboratories in resource-poor countries have been one of the most neglected components of health systems. ${ }^{1}$ The Strengthening Laboratory Management Toward Accreditation (SLMTA) programme was developed in an effort to improve the quality of laboratories throughout the developing world. It is a competency-based training programme designed to enable laboratories to implement practical quality management systems (QMS) and encourage continuous quality improvement.

Since its introduction in 2009, the SLMTA programme has been implemented widely throughout Africa, as well as in the Caribbean, Central and South America, and Southeast Asia. ${ }^{2}$ The primary focus of the programme thus far has been implementation and expansion; until recently, little attention has been paid to the systematic examination of programme results in order to guide programme improvement and decision making.

This systematic literature review aims to compile existing results from evaluations of the SLMTA programme into a comprehensive report, in order to provide a broad view of the programme and to identify directions for the future. Because of the large volume of information collected, the review has been published in two parts. In Part 1, published separately, we present content analysis of qualitative findings and identified strategic directions for future priorities. ${ }^{3}$ In this companion paper, we compile the quantitative data presented in the publications, examine scores and indicators, and conduct a meta-analysis of selected results in order to establish a solid, data-driven foundation for programme improvement and to help guide future implementation. 


\section{Research methods and design}

A comprehensive search of electronic bibliographic databases was performed, as described in Part 1. ${ }^{3}$ We included all published and in-press studies that discussed the SLMTA programme.

The standard SLMTA implementation model includes three workshops, each of which is followed by a period of several months for laboratories to implement improvement projects, usually with onsite support and mentorship. ${ }^{2}$ Laboratories implementing the SLMTA programme are evaluated through audits based on the Stepwise Laboratory Quality Improvement Process Towards Accreditation (SLIPTA) checklist. ${ }^{4}$ Audit scores are categorised into star ratings, with zero stars corresponding to a score of $0 \%-54 \%$, one star $55 \%-64 \%$, two stars $65 \%-74 \%$, three stars $75 \%-84 \%$, four stars $85 \%$ - 94\%, and five stars $95 \%-100 \%$. The checklist items are divided into 12 sections that represent the 12 Quality System Essentials (QSEs) as defined by the Clinical and Laboratory Standards Institute (CLSI). ${ }^{5}$ These QSEs can be grouped by stages of the quality cycle: Resource Management (equipment; facilities and safety; organisation and personnel; purchasing and inventory), Process Management (client management; documents and records; information management; process control and internal/ external quality assessment) and Improvement Management (corrective action; internal audit; management reviews; occurrence management). ${ }^{6}$ To assess progress, baseline and exit audits are conducted before and after SLMTA implementation, respectively, using the SLIPTA checklist. 'Surveillance' audits are also often conducted after the exit audit in order to monitor continued improvement and assess sustainability.

Several studies provided scores by individual QSEs. We combined these data and conducted a meta-analysis in Microsoft ${ }^{\circledR}$ Excel 2013 so as to determine common areas of strength, weakness and improvement. For studies reporting only median or mean QSE data for multiple laboratories, laboratory-level data were solicited from authors to further enhance the analysis. All cost estimates reported in local currency in published articles were converted into US dollars, based on the official exchange rate as of August 1, 2014. Percent changes in indicator results were calculated from published results if not reported directly in the papers.

\section{Results and discussion Literature search results}

We identified 28 published articles on the SLMTA programme ${ }^{2,7-33}$ (Table 1). In total, these studies included detailed information on SLMTA implementation in 211 laboratories in 18 countries, as well as global summary data from all 617 laboratories in the 47 countries that have implemented SLMTA as of the end of 2013.

TABLE 1: Characteristics of published SLMTA studies.

\begin{tabular}{|c|c|c|c|c|}
\hline Study & Country/Countries & Level of study & Number of laboratories & Years of study \\
\hline Andiric et al. ${ }^{7}$ & Tanzania & Select laboratory & 1 & $2010-2011$ \\
\hline Audu et al. ${ }^{8}$ & Nigeria & Select laboratories & 2 & 2010-2013 \\
\hline Eno et al. ${ }^{9}$ & Cameroon & Select hospital & 1 & $2011-2012$ \\
\hline Gachuki et al. ${ }^{10}$ & Kenya & Select laboratory & 1 & 2010-2013 \\
\hline Guevara et al. ${ }^{11}$ & $\begin{array}{l}\text { Bahamas, Jamaica, Barbados, } \\
\text { Trinidad and Tobago }\end{array}$ & One cohort & 5 & 2011-2013 \\
\hline Hiwotu et al. ${ }^{12}$ & Ethiopia & Two cohorts & 45 & 2010-2012 \\
\hline Lulie et al. ${ }^{13}$ & Ethiopia & Select laboratories & 17 & 2013 \\
\hline Maina et al. ${ }^{14}$ & Kenya & Select laboratories & 5 & $2011-2012$ \\
\hline Makokha et al. ${ }^{15}$ & Kenya & Select laboratories & 8 & $2010-2011$ \\
\hline Maruta et al. ${ }^{16}$ & NA & Global & NA & 2009-2013 \\
\hline Maruti et al. ${ }^{17}$ & Kenya & Select laboratory & 1 & $2011-2013$ \\
\hline Masamha et al. ${ }^{18}$ & Mozambique & One cohort & 8 & 2010-2012 \\
\hline Mataranyika et al. ${ }^{19}$ & Namibia & One cohort & 6 & $2012-2013$ \\
\hline Mokobela et al. ${ }^{20}$ & Bostwana & One cohort & 7 & $2010-2011$ \\
\hline Mothabeng et al. ${ }^{21}$ & Lesotho & Two cohorts & 18 & 2010-2011 \\
\hline Ndasi et al..$^{22}$ & Cameroon & One cohort & 5 & 2009-2012 \\
\hline Nguyen et al. ${ }^{23}$ & Vietnam and Cambodia & General & NA & $2012-2013$ \\
\hline Nkengasong et al. ${ }^{24}$ & NA & General & NA & NA \\
\hline Nkrumah et al. ${ }^{25}$ & Ghana & Three cohorts & 15 & $2011-2013$ \\
\hline Nkwawir et al. ${ }^{26}$ & Cameroon & Select laboratory & 1 & 2009-2013 \\
\hline Noble et al. ${ }^{27}$ & NA & General & NA & NA \\
\hline Ntshambiwa et al. ${ }^{28}$ & Bostwana & Select laboratory & 1 & $2010-2013$ \\
\hline Nzabahimana et al. ${ }^{29}$ & Rwanda & Three cohorts & 15 & 2010-2013 \\
\hline Nzombe et al. ${ }^{30}$ & Zimbabwe & One cohort & 19 & 2010-2012 \\
\hline Shumba et al. ${ }^{31}$ & Zimbabwe & Two cohorts & 30 & 2010-2012 \\
\hline Yao et al..$^{32}$ & NA & General & NA & NA \\
\hline Yao et al. ${ }^{2}$ & NA & General & NA & 2009-2013 \\
\hline Yao et al..$^{33}$ & 47 countries* & Global & 617 & 2010-2013 \\
\hline
\end{tabular}

Source: Luman, Yao and Nkengasong ${ }^{3}$

SLurce: Luman, Yao and Nkengasong ${ }^{3}$ SLMTA, Strengthening Laboratory Management Toward Accreditation; NA, not applicable.

*Angola, Antigua, Bahamas, Barbados, Belize, Botswana, Burundi, Cambodia, Cameroon, Columbia, Costa Rica, Cote d'Ivoire, Democratic Republic of the Congo, Dominica, Dominican Republic, El Salvador, Ethiopia, Ghana, Grenada, Guatemala, Haiti, Honduras, Jamaica, Kenya, Lesotho, Malawi, Mozambique, Namibia, Nicaragua, Nigeria, Panama, Peru, Rwanda, Sierra Leone, South Africa, South Sudan, Saint Kitts, Saint Lucia, Saint Vincent, Suriname, Swaziland, Tanzania, Trinidad and Tobago, Uganda, Vietnam, Zambia, Zimbabwe. 


\section{Global programme results}

Data from all laboratories implementing the SLMTA programme were collated and summarised in a single paper describing the global results of the programme to date. ${ }^{33}$ In total, 617 laboratories in 47 countries on four continents have implemented SLMTA in 65 training cohorts, with nearly 2000 laboratory staff trained in the programme. Most of the laboratories were at the district (38\%), regional (27\%) or national $(18 \%)$ levels. The authors report that the starting level of laboratory quality in developing countries was very low, with $84 \%$ of SLMTA laboratories scoring below the one-star level at baseline. The 302 laboratories that had completed the programme had an average improvement of 25 percentage points; $70 \%$ achieved at least one star at exit audit and $22 \%$ of laboratories increased three or more star levels.

Estimates of the number of laboratory tests conducted by SLMTA laboratories suggested that the 617 laboratories enrolled in SLMTA conduct more than 100 million tests annually and that whilst only $16 \%$ of these tests were conducted by laboratories with at least one quality star before SLMTA, 68\% were done by laboratories with at least one star after SLMTA implementation. That translates to approximately 58 million tests conducted by laboratories with little to no QMS prior to SLMTA which now have at least a basic quality system in place..$^{33}$

\section{Quality System Essentials meta-analysis}

Examining individual SLIPTA checklist scores for each of the 12 QSEs enables laboratories to pinpoint strengths, weaknesses and areas of improvement. QSE data have not been compiled systematically on a global scale. From the published papers, QSE data were presented for 126 laboratories in 12 countries. . $^{811,12,14,15,18,20,21,22,25,26}$ Individual studies reported substantial variability in high- and lowscoring QSEs. For example, some laboratories scored $0 \%$ for five of the 12 QSEs at exit audit, whereas others scored $100 \%$ for the same five QSEs.

At baseline, the weakest areas overall were in the Improvement Management stage of the quality cycle, including internal audit (5\%), occurrence management (16\%), corrective action (25\%) and management reviews (29\%) (Figure 1). At an average of $20 \%$, this stage scored less than half of the other two stages, namely, Resource Management (42\%) and Process Management (40\%). None of the 12 QSEs had mean baseline scores above 55\%; the highest scores were in information management (51\%), facilities and safety $(47 \%)$, purchasing and inventory $(42 \%)$ and process control and internal/external quality assessment (41\%).

At the exit audit, the four Improvement Management QSEs still showed the lowest scores, ranging from 32\% - 50\% (average 42\%) (Figure 1). The Resource Management and Process Management stages had higher scores ranging from $58 \%$ - 74\% (average 65\% for Resource Management and $63 \%$ for Process Management). The greatest improvements were in documents and records ( 34 percentage points), client management (29 percentage points), and facilities and safety (27 percentage points). Each of the three stages had the same average improvement of 23 percentage points.

Based on results from five laboratories, Maina et al. found that the laboratories with the greatest overall score increases had focused on internal audit and corrective action; they then hypothesised that an improvement in these areas may be a catalyst for overall improvement in other areas. ${ }^{14}$ Metaanalysis results suggest that the corrective action QSE may

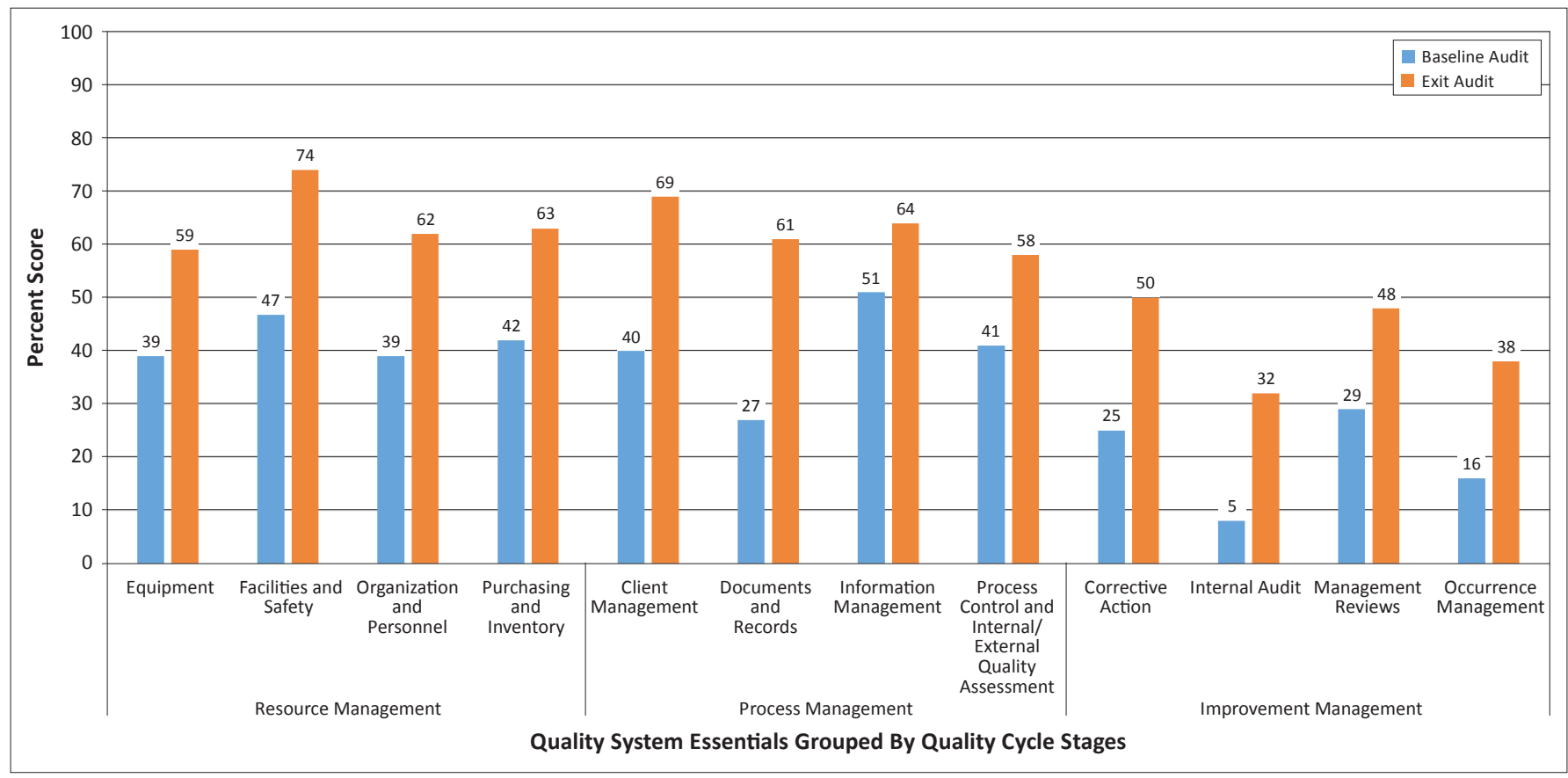

FIGURE 1: Baseline and exit audit scores for Quality System Essentials grouped by quality cycle stage from 126 laboratories in 12 countries. 
be the most predictive of overall improvement; laboratories in the top quartile of overall improvement outperformed those in the bottom quartile by 62 percentage points for the corrective action QSE, compared to a median of 40 percentage points for the other QSEs. CLSI defines corrective action as an 'action to eliminate the (root) cause of a detected nonconformity or other undesirable situation'. ${ }^{34}$ In the SLIPTA checklist, corrective action is assessed through four questions about how the laboratory deals with occurrence reports, nonconformities and discordant results. ${ }^{4}$ The International Organization for Standardization (ISO) confirms the importance of corrective action, saying that 'the corrective and preventive actions system is the most critical element for an efficient quality system ${ }^{\prime}{ }^{35}$ Additional work is needed to verify priority areas of improvement, as well as to delineate the set of essential improvement projects that will result in meaningful laboratory quality improvement.

\section{Official WHO AFRO SLIPTA audits and accreditation}

A July 2009 survey of accrediting body registers identified 340 accredited laboratories in sub-Saharan Africa; only 28 (8\%) of these laboratories were located outside of South Africa and nearly all were private, parastatal or donor-supported research facilities. ${ }^{36}$ By early 2013, little progress had been made, with 380 laboratories accredited in the region; only 35 (9\%) laboratories outside of South Africa were accredited and three quarters of the 49 countries in the region had no accredited laboratories. ${ }^{37}$ However, the impact of SLMTA is beginning to show; as of September 2014, six laboratories enrolled in SLMTA in Kenya, the Bahamas, Vietnam and Zimbabwe have been accredited, at a median of 31.5 months after starting the SLMTA programme. ${ }^{10,11,33}$ Several laboratories have been recommended for accreditation or are

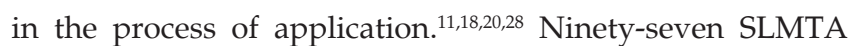
laboratories have received official WHO AFRO SLIPTA audits conducted by representatives from the African Society for Laboratory Medicine, ${ }^{33}$ including 11 laboratories in published reports included in this review.7,18,25,26,29

\section{Service delivery indicators}

In addition to audit scores, many of the studies reported improvements for indicators reflecting testing and customer and clinician satisfaction (Table 2). Three studies reported reductions in turnaround time for testing, ${ }^{10,20,28}$ with times decreasing by $19 \%$ - 95\%. Patient and clinician satisfaction were commonly measured using surveys. Four studies showed relative improvements in patient satisfaction ranging from $30 \%$ to $>100 \%, 9,10,25,28$ although in one laboratory complaints from patients increased, possibly as a result of staff attrition. ${ }^{17}$ Two studies reporting on clinician satisfaction found improvements of approximately $80 \% .{ }^{17,28}$

Indicators for laboratory management and overall functioning also showed improvements (Table 2). One laboratory reported a $65 \%$ decrease in corrective actions, ${ }^{10}$ five laboratories in the Caribbean Region reported decreases in nonconformities of $50 \%-66 \%{ }^{11}$ and two laboratories showed improvements in external quality assessment results of $67 \%-85 \% .^{10,17}$ In a Kenyan laboratory, staff punctuality increased $67 \%$ and the need for equipment repairs decreased $63 \%{ }^{17}$ A Botswana laboratory successfully reduced losses resulting from expired reagents from $\$ 18000$ in 2010 to $\$ 40$ in $2013,{ }^{28}$ and three studies showed reductions in specimen rejection rates of $69 \%-93 \% .10,17,25$ When SLMTA was adapted and implemented at a hospital in Cameroon, patient wait times decreased $67 \%-83 \%$, infection rates and stillborn rates decreased ( $83 \%$ and $80 \%$, respectively) and the number of patients and hospital revenue increased. ${ }^{9}$

\section{Cost}

The reported costs per laboratory of implementing various components of SLMTA have varied widely (Table 3). Much of this variability is because of differences in what was included in the cost estimates, as well as location-specific factors, such the price of fuel, salary levels and distances to participating laboratories. The estimated cost of conducting the three-workshop SLMTA series has ranged from \$1482 per laboratory in Zimbabwe using local facilitators in a central location $^{31}$ to $\$ 21480$ in Cameroon using decentralised training. ${ }^{22}$ Mentorship cost per laboratory has ranged from $\$ 5689$ in Zimbabwe ${ }^{30}$ to $\$ 24000$ in Ghana. ${ }^{25}$ The cost of implementing improvement projects has ranged from $\$ 10000$ in Ghana ${ }^{25}$ to $\$ 36500$ in a Kenyan laboratory seeking accreditation. ${ }^{10}$

Three studies have compared the cost of various SLMTA implementation models. One study of 19 laboratories in Zimbabwe found that mentorship and supervision costs for four different models were similar (\$5689-\$9601 per laboratory), recommending that 'countries should carefully consider which mentorship model or models would be best suited to their individual situation'. ${ }^{30}$ Another study in Zimbabwe found that implementing SLMTA using local (in-country) facilitators is more expensive than external facilitators for the first SLMTA cohort because of the costs associated with conducting an in-country training-oftrainers; however, over the course of national scale-up in 120 laboratories, use of local facilitators would save the country nearly 50\% (\$580 000 vs. \$322 000). ${ }^{31}$ A Cameroonian study found that the cost per laboratory of centralised training was approximately the same as decentralised training (\$21 122 vs. \$21 480, respectively); centralised training required less trainer time, whilst decentralised training allowed more staff to participate. ${ }^{22}$

No published studies to date have reported a thorough examination of the cost of implementing the entire SLMTA programme, including each of the major components (training of mentors, trainers and auditors; conducting SLMTA workshops; mentorship, supervisory visits and implementation of improvement projects; and conducting audits). In addition, a more extensive cost-benefit analysis taking into consideration the value of laboratorians' time (i.e., opportunity cost) to participate in the programme and 
TABLE 2: Health service indicators associated with SLMTA implementation as reported in published studies.

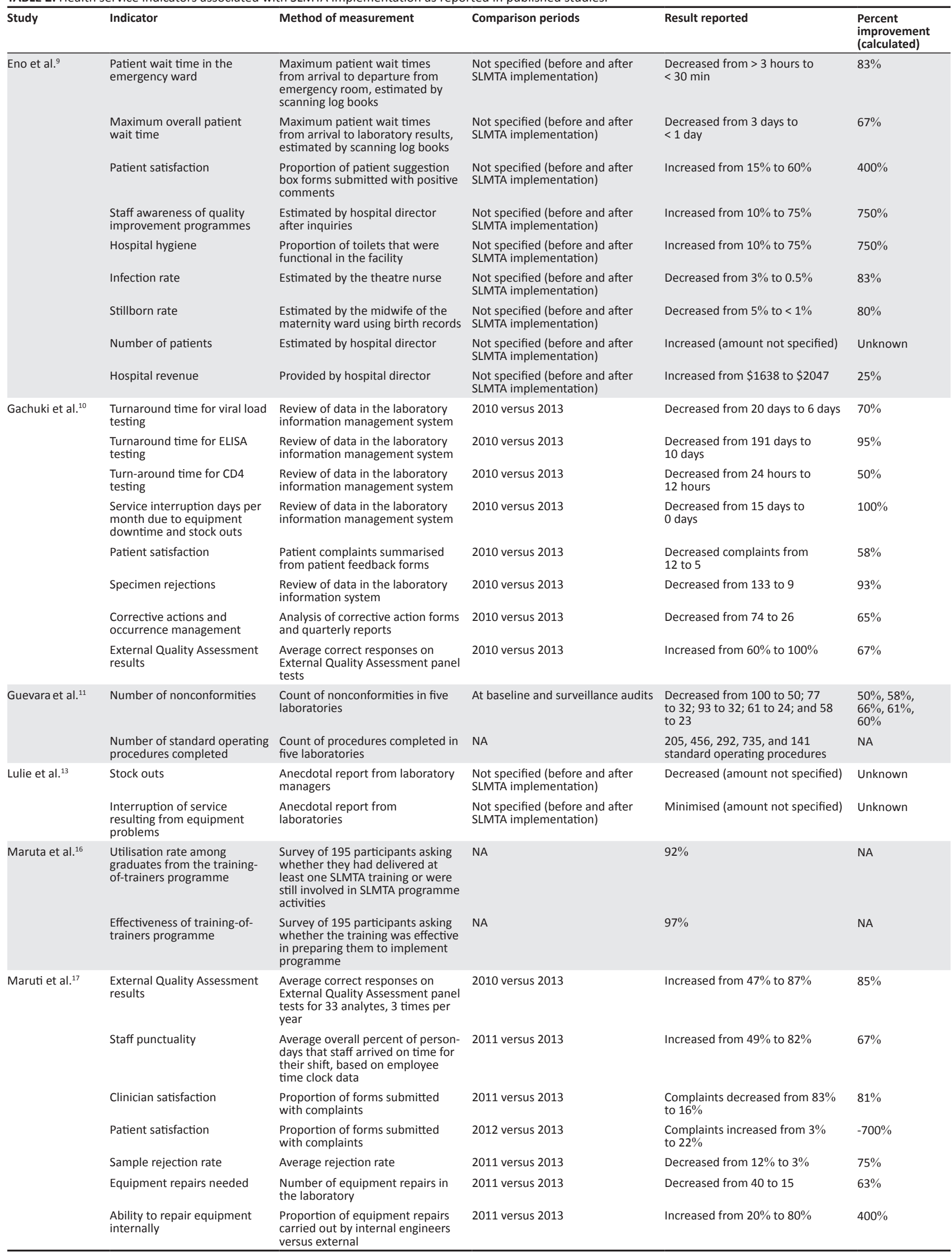

SLMTA, Strengthening Laboratory Management Toward Accreditation; ELISA, enzyme-linked immunosorbent assay; NA, not applicable; CSF, cerebrospinal fluid. 
TABLE 2 (Continues...): Health service indicators associated with SLMTA implementation as reported in published studies.

\begin{tabular}{|c|c|c|c|c|c|}
\hline Study & Indicator & Method of measurement & Comparison periods & Result reported & $\begin{array}{l}\text { Percent } \\
\text { improvement } \\
\text { (calculated) }\end{array}$ \\
\hline Mokobela et al. ${ }^{20}$ & $\begin{array}{l}\text { Turnaround time for } \\
\text { laboratory testing }\end{array}$ & $\begin{array}{l}\text { Anecdotal report from } \\
\text { laboratories }\end{array}$ & $\begin{array}{l}\text { Not specified (before and after } \\
\text { SLMTA implementation) }\end{array}$ & Decreased (amount not given) & Unknown \\
\hline \multirow[t]{2}{*}{ Nkrumah et al. ${ }^{25}$} & Specimen rejection rates & $\begin{array}{l}\text { Percentage of total number of } \\
\text { samples rejected, averaged over } \\
\text { four laboratories }\end{array}$ & 2011-2013 & Decreased from $32 \%$ to $10 \%$ & $69 \%$ \\
\hline & Patient satisfaction & $\begin{array}{l}\text { Proportion of patient suggestion } \\
\text { box forms submitted with positive } \\
\text { comments, averaged over four } \\
\text { laboratories }\end{array}$ & 2011-2013 & Increased from $25 \%$ to $70 \%$ & $300 \%$ \\
\hline \multirow[t]{8}{*}{$\begin{array}{l}\text { Ntshambiwa } \\
\text { et al. }{ }^{28}\end{array}$} & $\begin{array}{l}\text { Turnaround time for } \\
\text { haematology }\end{array}$ & $\begin{array}{l}\text { Analysis of results from the } \\
\text { Integrated Patient Management } \\
\text { System }\end{array}$ & $\begin{array}{l}\text { April - September } 2011 \text { versus } \\
\text { October } 2011 \text { - March } 2012\end{array}$ & $\begin{array}{l}\text { Decreased from } 72 \text { minutes to } 58 \\
\text { minutes }\end{array}$ & $19 \%$ \\
\hline & $\begin{array}{l}\text { Turnaround time for } \\
\text { chemistry }\end{array}$ & $\begin{array}{l}\text { Analysis of results from the } \\
\text { Integrated Patient Management } \\
\text { System }\end{array}$ & $\begin{array}{l}\text { April - September } 2011 \text { versus } \\
\text { October } 2011 \text { - March } 2012\end{array}$ & $\begin{array}{l}\text { Decreased from } 154 \text { minutes to } \\
86 \text { minutes }\end{array}$ & $44 \%$ \\
\hline & Turnaround time for CSF & $\begin{array}{l}\text { Analysis of results from the } \\
\text { Integrated Patient Management } \\
\text { System }\end{array}$ & $\begin{array}{l}\text { April - September } 2011 \text { versus } \\
\text { October } 2011 \text { - March } 2012\end{array}$ & $\begin{array}{l}\text { Decreased from } 152 \text { minutes to } \\
106 \text { minutes }\end{array}$ & $30 \%$ \\
\hline & $\begin{array}{l}\text { Turnaround time for } \\
\text { pregnancy tests }\end{array}$ & $\begin{array}{l}\text { Analysis of results from the } \\
\text { Integrated Patient Management } \\
\text { System }\end{array}$ & $\begin{array}{l}\text { April - September } 2011 \text { versus } \\
\text { October } 2011 \text { - March } 2012\end{array}$ & $\begin{array}{l}\text { Decreased from } 97 \text { minutes to } 46 \\
\text { minutes }\end{array}$ & $52 \%$ \\
\hline & Patient satisfaction & $\begin{array}{l}\text { Proportion of patients indicating } \\
\text { 'good' or 'very good' on survey } \\
\text { forms }\end{array}$ & 2011 versus 2013 & Increased from $56 \%$ to $73 \%$ & $30 \%$ \\
\hline & Clinician satisfaction & $\begin{array}{l}\text { Proportion of clinicians indicating } \\
\text { 'good' or 'very good' on survey } \\
\text { forms }\end{array}$ & 2011 versus 2013 & Increased from $41 \%$ to $72 \%$ & $76 \%$ \\
\hline & Reagent wastage & $\begin{array}{l}\text { Calculated laboratory losses } \\
\text { resulting from expired reagents }\end{array}$ & Fiscal year 2011 versus 2013 & Decreased from $\$ 18000$ to $\$ 40$ & $>99 \%$ \\
\hline & $\begin{array}{l}\text { Number of standard operating } \\
\text { procedures completed }\end{array}$ & Count of procedures completed & NA & $\begin{array}{l}154 \text { standard operating } \\
\text { procedures }\end{array}$ & NA \\
\hline
\end{tabular}

SLMTA, Strengthening Laboratory Management Toward Accreditation; ELISA, enzyme-linked immunosorbent assay; NA, not applicable; CSF, cerebrospinal fluid.

implement changes in the laboratory along with tangible and intangible benefits of the programme is needed. ${ }^{31}$

\section{Limitations to the study}

This review is subject to several limitations. Firstly, whilst 28 studies on SLMTA were identified and summarised, these reflect only 18 (38\%) of the 47 countries and 211 (34\%) of the 617 laboratories that have implemented the programme. Their results may not be representative of the programme as a whole, or a comprehensive account of all laboratories' experiences. Secondly, whilst audit results were available for all laboratories because of the use of the SLIPTA checklist, the other indicators presented here were available in few of the published studies; in addition, methodologies varied between the studies, limiting the ability to combine and compare results directly.

Authors of the studies published thus far also point out several limitations. Firstly, the SLMTA programme as a whole is too young to allow an assessment of the long-term sustainability of results. ${ }^{14,33}$ Secondly, all of the published studies were observational; several studies examining the effect of mentorship or training methodologies note that laboratories were not assigned randomly, but were rather selected purposively based on convenience or other programmatic considerations. Thus there may have been other factors that could account for some of the differences. ${ }^{8,15,20,30}$ Similarly, none of the studies included control laboratories upon which to base a comparison..$^{22}$ Thirdly, there is a lack of consistency in the qualifications of auditors; whilst the SLIPTA checklist is designed to help standardise the audit process, some variability between auditors may remain. ${ }^{8,29}$ Finally, several authors noted that their published studies are based on a small number of laboratories ${ }^{14,15,20,30}$ and some indicators were either not measured systematically ${ }^{9}$ or not measured at baseline. ${ }^{9,28}$

\section{Conclusion}

In their summary of global-level findings, Yao et al. point out that 'few [other] management and leadership development programmes have been implemented on a such a large scale with results-oriented outcome measures' ${ }^{33}$ The wide array of results reported provides a comprehensive picture of the SLMTA programme overall, suggesting a substantive impact on provision of quality laboratory services and patient care. The full potential of the programme can be realised only if the lessons learned lead to informed action among laboratory workers, healthcare providers and policy makers toward the ultimate goal of providing quality patient care.

\section{Acknowledgements}

We would like to thank the lead authors of the in-press papers for allowing us to examine their results prior to publication, making it possible to publish this review simultaneously with their work: Linda Andiric, Rosemary Audu, Laura Eno, Thomas Gachuki, Giselle Guevara, Tilahun Hiwotu, Adino Lulie, Robert Maina, Ernest Makokha, Talkmore Maruta, Phidelis Maruti, Jessina Masamha, Mary Mataranyika, Kelebeletse Mokobela, Juliana Ndasi, Thuong Nguyen, Bernard Nkrumah, Siyem 
TABLE 3: Cost estimates of various components of SLMTA implementation as reported in published studies.

\begin{tabular}{|c|c|c|c|c|c|c|}
\hline Study & $\begin{array}{l}\text { Portion of programme } \\
\text { evaluated }\end{array}$ & Included costs & Excluded costs & Category & Component & $\begin{array}{r}\text { Estimated cost } \\
\text { per laboratory (US\$) }\end{array}$ \\
\hline \multirow[t]{3}{*}{ Gachuki et al. ${ }^{9}$} & \multirow{3}{*}{$\begin{array}{l}\text { Post-SLMTA to achieve ISO } \\
15189 \text { accreditation }\end{array}$} & \multirow{3}{*}{$\begin{array}{l}\text { Fees paid to the } \\
\text { accrediting body, } \\
\text { improvement projects }\end{array}$} & \multirow{3}{*}{$\begin{array}{l}\text { In-kind mentorship, SLMTA } \\
\text { implementation, staff time }\end{array}$} & \multirow{3}{*}{ Single laboratory } & Accreditation fees & 7000 \\
\hline & & & & & Improvement projects & 29500 \\
\hline & & & & & Total & 36500 \\
\hline \multirow[t]{4}{*}{ Ndasi et al. ${ }^{21}$} & \multirow[t]{4}{*}{ Workshops } & \multirow{4}{*}{$\begin{array}{l}\text { Lodging, per diem, } \\
\text { transportation, training } \\
\text { materials, food, venue hire }\end{array}$} & \multirow{4}{*}{$\begin{array}{l}\text { Other components of } \\
\text { SLMTA implementation } \\
\text { (mentorship, supervision, } \\
\text { improvement projects, } \\
\text { audits), salaries }\end{array}$} & \multirow[t]{2}{*}{ Centralised } & $\begin{array}{l}\text { SLMTA workshops per } \\
\text { participant }\end{array}$ & 4225 \\
\hline & & & & & $\begin{array}{l}\text { SLMTA workshops per } \\
\text { laboratory }\end{array}$ & 21122 \\
\hline & & & & \multirow[t]{2}{*}{ Decentralised } & $\begin{array}{l}\text { SLMTA workshops per } \\
\text { participant }\end{array}$ & 895 \\
\hline & & & & & $\begin{array}{l}\text { SLMTA workshops per } \\
\text { laboratory }\end{array}$ & 21480 \\
\hline \multirow[t]{4}{*}{ Nkrumah et al. ${ }^{24}$} & \multirow{4}{*}{$\begin{array}{l}\text { Mentorship, workshops } \\
\text { and improvement projects }\end{array}$} & \multirow{4}{*}{$\begin{array}{l}\text { Programme implementer } \\
\text { costs for mentors' salaries, } \\
\text { SLMTA workshops, and } \\
\text { improvement projects }\end{array}$} & \multirow[t]{4}{*}{ Not indicated } & \multirow[t]{4}{*}{ Per laboratory } & Mentorship & 24000 \\
\hline & & & & & SLMTA workshops & 6000 \\
\hline & & & & & $\begin{array}{l}\text { Improvement project } \\
\text { support }\end{array}$ & 10000 \\
\hline & & & & & Total & 40000 \\
\hline \multirow[t]{12}{*}{ Nzombe et al. ${ }^{28}$} & \multirow[t]{12}{*}{ Mentorship } & \multirow{12}{*}{$\begin{array}{l}\text { Mentor training, salaries, } \\
\text { travel, lodging, internet } \\
\text { access, equipment }\end{array}$} & \multirow{12}{*}{$\begin{array}{l}\text { All other components of } \\
\text { SLMTA implementation } \\
\text { (workshops, improvement } \\
\text { projects, audits, staff time) }\end{array}$} & \multirow{3}{*}{$\begin{array}{l}\text { Model 1: Laboratory } \\
\text { Manger Mentorship after } \\
\text { SLMTA (per laboratory) }\end{array}$} & Mentorship & 5486 \\
\hline & & & & & Supervision & 928 \\
\hline & & & & & Total & 6414 \\
\hline & & & & \multirow{3}{*}{$\begin{array}{l}\text { Model 2: One Week per } \\
\text { Month Mentorship after } \\
\text { SLMTA (per laboratory) }\end{array}$} & Mentorship & 4761 \\
\hline & & & & & Supervision & 928 \\
\hline & & & & & Total & 5689 \\
\hline & & & & \multirow{3}{*}{$\begin{array}{l}\text { Model 3: Cyclical } \\
\text { Embedded Mentorship } \\
\text { after SLMTA (per } \\
\text { laboratory) }\end{array}$} & Mentorship & 9137 \\
\hline & & & & & Supervision & 464 \\
\hline & & & & & Total & 9601 \\
\hline & & & & \multirow{3}{*}{$\begin{array}{l}\text { Model 4: Cyclical } \\
\text { Embedded Mentorship } \\
\text { with SLMTA (per } \\
\text { laboratory) }\end{array}$} & Mentorship & 9137 \\
\hline & & & & & Supervision & 464 \\
\hline & & & & & Total & 9601 \\
\hline \multirow[t]{14}{*}{ Shumba, et al..$^{30}$} & \multirow{14}{*}{$\begin{array}{l}\text { Workshops, supervision } \\
\text { and audits; training of } \\
\text { local facilitators }\end{array}$} & \multirow{14}{*}{$\begin{array}{l}\text { Direct costs borne by } \\
\text { programme implementer: } \\
\text { training equipment, } \\
\text { training (facilities and } \\
\text { materials), trainers and } \\
\text { supervisors (transport, } \\
\text { accommodation, per- } \\
\text { diem and fees) and } \\
\text { participants (transport, } \\
\text { accommodation and per- } \\
\text { diem) }\end{array}$} & In-kind contributions and & External facilitators (per & Baseline audits & 227 \\
\hline & & & $\begin{array}{l}\text { salaries of local facilitators } \\
\text { and trainees }\end{array}$ & & SLMTA workshops & 3634 \\
\hline & & & & & Supervision & 400 \\
\hline & & & & & Exit audits & 1540 \\
\hline & & & & & Total & 5801 \\
\hline & & & & Internal facilitators (per & Baseline audits & 7 \\
\hline & & & & laboratory) & SLMTA workshops & 1372 \\
\hline & & & & & Supervision & 74 \\
\hline & & & & & Exit audits & 29 \\
\hline & & & & & Total & 1482 \\
\hline & & & & & Facilitator training & 4444 \\
\hline & & & & $\begin{array}{l}\text { Theoretical, external } \\
\text { facilitators (per laboratory) }\end{array}$ & Total & 4837 \\
\hline & & & & $\begin{array}{l}\text { Theoretical, internal } \\
\text { facilitators (per laboratory) }\end{array}$ & $\begin{array}{l}\text { Total, first cohort (includes } \\
\text { facilitator training) }\end{array}$ & 8396 \\
\hline & & & & & Total, subsequent cohorts & 1263 \\
\hline
\end{tabular}

SLMTA, Strengthening Laboratory Management Toward Accreditation; ISO, International Organization for Standardization.

Nkwawir, Michael Noble, Keoratile Ntshambiwa, Innocent Nzabahimana, Phoebe Nzombe and Edwin Shumba. Special thanks go to Philip Rotz, Lee Schroeder, Bethanie Rammer and Penny Smorenburg for their valuable feedback in manuscript revision.

This research has been supported by the President's Emergency Plan for AIDS Relief (PEPFAR) through the CDC.

\section{Competing interests}

The authors declare that they have no financial or personal relationship(s) that may have inappropriately influenced them in writing this article.

\section{Authors' contributions}

E.T.L (CDC, Atlanta) analysed the data and wrote the manuscript. K.Y. (CDC, Atlanta) and J.N.N (CDC, Atlanta) provided substantial input to the revision of the manuscript.

\section{CDC disclaimer}

The findings and conclusions in this report are those of the authors and do not necessarily represent the official position of the CDC.

\section{References}

1. Nkengasong JN, Nsubuga $P$, Nwanyanwu $O$, et al. Laboratory systems and services are critical in global health: Time to end the neglect? Am J Clin Pathol. 2010;134(3):368-373. 
2. Yao K, Maruta T, Luman ET, Nkengasong JN. The SLMTA programme: Transforming the laboratory landscape in developing countries. Afr J Lab Med. 2014:3(2), Art. \#194, 8 pages. http://dx.doi.org/10.4102/ajlm.v3i2.194

3. Luman ET, Yao K, Nkengasong JN. A comprehensive review of the SLMTA literature part 1: Content analysis and future priorities. Afr J Lab Med. 2014;3(2), Art. \#265, 11 pages. http://dx.doi.org/10.4102/ajlm.v3i2.265

4. World Health Organization Regional Office for Africa. WHO Guide for the Stepwise Laboratory Improvement Process Towards Accreditation in the African Region (with checklist) [document on the Internet]. c2011 [cited 2014 Jul]. Available from: http://www.afro.who.int/en/clusters-a-programmes/hss/bloodsafety-laboratories-a-health-technology/blt-highlights/3859-who-guide-for-thestepwise-laboratory-improvement-process-towards-accreditation-in-the-africanregion-with-checklist.html

5. Clinical and Laboratory Standards Institute. Application of a quality management system model for laboratory services; Approved Guidelines - Third Edition. CLSI document GP26-A3 [ISBN 1-56238-553-4]. Wayne, PA: Clinical and Laboratory Standards Institute; 2004

6. Datema T, Oskam L, van Beers SM, et al. Critical review of the Stepwise Laboratory Improvement Process Towards Accreditation (SLIPTA): Suggestion for harmonization, implementation and improvement. Trop Med Int Health. 2012;17(3):361-367.

7. Andiric LR, Massambu CG. One laboratory's progress toward accreditation in Tanzania. Afr J Lab Med. 2014;3(2), Art. \#202, 4 pages. http://dx.doi.org/10.4102/ ajlm.v3i2.202

8. Audu RA, Onubogu CC, Nwokoye NN, et al. Improving quality in national reference laboratories: The role of SLMTA and mentorship. Afr J Lab Med. 2014;3(2), Art. \#200, 7 pages. http://dx.doi.org/10.4102/ajlm.v3i2.200

9. Eno LT, Asong T, Ngale E, et al. Driving hospital transformation with SLMTA in a regional hospital in Cameroon. Afr J Lab Med. 2014;3(2), Art. \#221, 5 pages. http://dx.doi.org/10.4102/ajlm.v3i2.221

10. Gachuki T, Sewe R, Mwangi J, et al. Attaining ISO 15189 accreditation through SLMTA: A journey by Kenya's National HIV Reference Laboratory. Afr J Lab Med. 2014;3(2), Art. \#216, 9 pages. http://dx.doi.org/10.4102/ajlm.v3i2.216

11. Guevara G, Gordon F, Irving Y, et al. The impact of SLMTA in improving laboratory quality systems in the Caribbean Region. Afr J Lab Med. 2014;3(2), Art. \#199, 9 pages. http://dx.doi.org/10.4102/ajlm.v3i2.199

12. Hiwotu TM, Ayana G, Mulugeta A, et al. Laboratory system strengthening and quality improvement in Ethiopia. Afr J Lab Med. 2014;3(2), Art. \#228, 6 pages. http://dx.doi.org/10.4102/ajlm.v3i2.228

13. Lulie $A D$, Hiwotu TM, Mulugeta $A$, et al. Perceptions and attitudes toward SLMTA amongst laboratory and hospital professionals in Ethiopia. Afr J Lab Med. 2014;3(2), Art. \#233, 6 pages. http://dx.doi.org/10.4102/ajlm.v3i2.233

14. Maina RN, Mengo DM, Mohamud AD, et al. Progressing beyond SLMTA: Are internal audits and corrective action the key drivers of quality improvement? Afr Lab Med. 2014;3(2), Art. \#222, 7 pages. http://dx.doi.org/10.4102/ajlm.v3i2.222

15. Makokha EP, Mwalili S, Basiye FL, et al. Using standard and institutional mentorship models to implement SLMTA in Kenya. Afr J Lab Med. 2014;3(2), Art. \#220, 8 pages. http://dx.doi.org/10.4102/ajlm.v3i2.220

16. Maruta T, Yao K, Ndlovu N, Moyo S. Training-of-trainers: A strategy to build country capacity for SLMTA expansion and sustainability. Afr J Lab Med. 2014;3(2) Art. \#196, 7 pages. http://dx.doi.org/10.4102/ajlm.v3i2.196

17. Maruti PM, Mulianga EA, Wambani LN, et al. Creating a sustainable culture of quality through the SLMTA programme in a district hospital laboratory in Kenya. Af J Lab Med. 2014;3(2), Art. \#201, 5 pages. http://dx.doi.org/10.4102/ajlm.v3i2.201

18. Masamha J, Skaggs B, Pinto I, et al. Working toward a sustainable laboratory quality improvement programme through country ownership: Mozambique's SLMTA story. Afr J Lab Med. 2014;3(2), Art. \#253, 6 pages. http://dx.doi. org/10.4102/ajlm.v3i2.253
19. Mataranyika MN, Beukes LK. View from the top: Involvement of Namibia's health ministry in laboratory quality improvement. Afr J Lab Med. 2014;3(2), Art. \#195, 2 pages. http://dx.doi.org/10.4102/ajlm.v3i2.195

20. Mokobela KO, Moatshe MT, Modukanele M. Accelerating the spread of laboratory quality improvement efforts in Botswana. Afr J Lab Med. 2014;3(2), Art. \#207, 6 pages. http://dx.doi.org/10.4102/ajlm.v3i2.207

21. Mothabeng $D$, Maruta $T$, Lebina $M$, et al. Strengthening laboratory management towards accreditation: the Lesotho experience. Afr J Lab Med. 2012;1(1), Art. \#9, 7 pages. http://dx. doi: 10.4102/ajlm.v1i1.9

22. Ndasi J, Dimite L, Mbome $V$, et al. Decentralised facility-based training as an alternative model for SLMTA implementation: The Cameroon experience. Afr J Lab Med. 2014;3(2), Art. \#231, 6 pages. http://dx.doi.org/10.4102/ajlm.v3i2.231

23. Nguyen TT, McKinney B, Pierson A, et al. SLIPTA e-Tool improves laboratory audit process in Vietnam and Cambodia. Afr J Lab Med. 2014;3(2), Art. \#219, 5 pages. http://dx.doi.org/10.4102/ajlm.v3i2.219

24. Nkengasong JN, Birx D. Quality matters in strengthening global laboratory medicine. Afr J Lab Med. 2014;3(2), Art. \#239, 4 pages. http://dx.doi.org/10.4102/ ajlm.v3i2.239

25. Nkrumah B, Van der Puije B, Bekoe V, et al. Building local human resources to implement SLMTA with limited donor funding: The Ghana experience. Afr J Lab Med. 2014;3(2), Art. \#214, 7 pages. http://dx.doi.org/10.4102/ajlm.v3i2.214

26. Nkwawir SC, Batumani NN, Maruta T, Awasom CN. From grass to grace: How SLMTA revolutionised the Bamenda Regional Hospital Laboratory in Cameroon. Afr J Lab Med. 2014;3(2), Art. \#203, 6 pages. http://dx.doi.org/10.4102/ajlm.v3i2.203

27. Noble MA, Martin R, Ndihokubwayo J-B. Making great strides in medical laboratory quality. Afr J Lab Med. 2014;3(2), Art. \#256, 2 pages. http://dx.doi.org/10.4102/ ajlm.v3i2.256

28. Ntshambiwa K, Ntabe-Jagwer W, Kefilwe C, et al. Translating a National Laboratory Strategic Plan into action through SLMTA in a district hospital laboratory in Botswana. Afr J Lab Med. 2014;3(2), Art. \#209, 5 pages. http://dx.doi.org/10.4102/ ajlm.v3i2.209

29. Nzabahimana I, Sebasirimu S, Gatabazi JB, et al. Innovative strategies for a successful SLMTA country programme: The Rwanda story. Afr J Lab Med. 2014;3(2), Art. \#217, 6 pages. $h$ ttp://dx.doi.org/10.4102/ajlm.v3i2.217

30. Nzombe $P$, Luman ET, Shumba E, et al. Maximising mentorship: Variations in laboratory mentorship models implemented in Zimbabwe. Afr J Lab Med. 2014;3(2) Art. \#241, 8 pages. http://dx.doi.org/10.4102/ajlm.v3i2.241

31. Shumba E, Nzombe P, Mbinda A, et al. Weighing the costs: Implementing the SLMTA programme in Zimbabwe using internal versus external facilitators. Afr J Lab Med. 2014;3(2), Art. \#248, 6 pages. http://dx.doi.org/10.4102/ajlm.v3i2.248

32. Yao K, McKinney B, Murphy A, et al. Improving quality management systems of laboratories in developing countries: An innovative training approach to accelerate laboratory accreditation. Am J Clin Pathol. 2010;134(3):401-409.

33. Yao K, Luman ET, SLMTA Collaborating Authors. Evidence from 617 laboratories in 47 countries for SLMTA-driven improvement in quality management systems. Afr Lab Med. 2014;3(2), Art. \#262, 11 pages. http://dx.doi.org/10.4102/ajlm.v3i2.262

34. Clinical Laboratory Standards Institute. Management of nonconforming laboratory events; approved guideline. CLSI document GP32-A. Wayne, PA: Clinical Laboratory Standards Institute; 2007.

35. International Organization for Standardization. ISO 9000 resources: corrective and preventive actions high level review [page on the Internet]. c2014 [cited 2014 Sep 18]. Available from: http://www.iso9000resources.com/ba/corrective-preventiveactions.cfm

36. Gershy-Damet G, Rotz P, Cross D, et al. The World Health Organization African region laboratory accreditation process: Improving the quality of laboratory systems in the African region. Am J Clin Pathol. 2010;134(3):393-400.

37. Schroeder LF, Amukele T. Medical laboratories in Sub-Saharan Africa that meet international quality standards. Am J Clin Pathol. 2014;141(6):791-795. 